\title{
Determination of the Dissociation Constants of 16 Active Ingredients in Medicinal Herbs Using a Liquid-Liquid Equilibrium Method
}

\author{
Wanying Wang ${ }^{\dagger}$, Baixiu Zheng ${ }^{\dagger}$, Jiahao Wu, Weisong Lv, Peiying Lin and Xingchu Gong *(D) \\ Pharmaceutical Informatics Institute, College of Pharmaceutical Sciences, Zhejiang University, \\ Hangzhou 310058, China; 21919074@zju.edu.cn (W.W.); 3180101012@zju.edu.cn (B.Z.); \\ 18868115215@163.com (J.W.); 3180101203@zju.edu.cn (W.L.); 3170104675@zju.edu.cn (P.L.) \\ * Correspondence: gongxingchu@zju.edu.cn; Tel./Fax: +86-(071)-88208426 \\ + Wanying Wang and Baixiu Zheng contributed equally to this work.
}

check for updates

Citation: Wang, W.; Zheng, B.; Wu, J.; Lv, W.; Lin, P.; Gong, X. Determination of the Dissociation Constants of 16 Active Ingredients in Medicinal Herbs Using a Liquid-Liquid Equilibrium Method. Separations 2021, 8, 49. https://doi.org/10.3390/ separations 8040049

Academic Editor:

Dorota Kwiatkowska

Received: 16 March 2021

Accepted: 9 April 2021

Published: 14 April 2021

Publisher's Note: MDPI stays neutral with regard to jurisdictional claims in published maps and institutional affiliations.

Copyright: (c) 2021 by the authors. Licensee MDPI, Basel, Switzerland. This article is an open access article distributed under the terms and conditions of the Creative Commons Attribution (CC BY) license (https:/ / creativecommons.org/licenses/by/ $4.0 /)$.

\begin{abstract}
The dissociation constant is an important physicochemical property of drug molecules that affects the pharmacokinetic and pharmacodynamic properties of drugs. In this study, the distribution coefficients of 16 active ingredients extracted from herbal materials were determined at different $\mathrm{pH}$ values in liquid-liquid equilibrium systems; the active ingredients were sinomenine, aescin $\mathrm{A}$, aescin $\mathrm{B}$, aescin $\mathrm{C}$, aescin $\mathrm{D}$, chlorogenic acid, neochlorogenic acid, cryptochlorogenic acid, isochlorogenic acid $A$, isochlorogenic acid $B$, isochlorogenic acid $C$, baicalin, wogonoside, calycosin-7-glucoside, astraisoflavan-7-O- $\beta$-D-glucoside, and isomucronulatol 7-O-glucoside. The dissociation constants of these active ingredients were calibrated and compared with reported values. The dissociation constants obtained were close to those reported in other studies, which means that the results of this work are reliable.
\end{abstract}

Keywords: liquid-liquid equilibrium method; dissociation constant; distribution coefficient; Caulis Sinomenii; Semen Aesculi; Flos Lonicerae; Radix Scutellariae; Radix Astragali

\section{Introduction}

The dissociation constant $\left(\mathrm{pK}_{\mathrm{a}}\right)$ of a drug molecule affects its adsorption, distribution, and metabolism. Therefore, $\mathrm{pK}_{\mathrm{a}}$ data are important data for drug molecules. The liquidliquid extraction [1], precipitation [2], adsorption [3], or percolation of drug compounds [4] are methods where the dissociation constants can be used in the process design and optimization. Accordingly, $\mathrm{pK}_{\mathrm{a}}$ data are useful for the pharmaceutical industry. The determination of $\mathrm{pK}_{\mathrm{a}}$ values is of great significance for the research and development of new drugs, production processes, and clinical pharmaceuticals.

Commonly used methods for determining $\mathrm{pK}_{\mathrm{a}}$ values include potentiometric titration [5], ultraviolet spectrophotometry [6], capillary electrophoresis [7], liquid chromatography [8], and conductivity methods [9]. The liquid-liquid equilibrium method can simultaneously determine the $\mathrm{pK}_{\mathrm{a}}$ and distribution coefficient $\left(D_{\mathrm{app}}\right)$ values of multiple active ingredients in a complex mixture [10], such as an herbal extract. The $D_{\text {app }}$ data are useful for the selection of an extractant [11]. When 1-octanol is used as the extractant to reach the liquid-liquid equilibrium, the $\log P$ data of the active ingredients can also be calibrated.

Sinomenine is the main active ingredient of Caulis Sinomenii, which has anti-inflammatory and immunosuppressive, analgesic and sedative, anti-arrhythmic, and antitumor activities [12]. Aescins are the main active ingredients of Semen Aesculi, which have various activities, such as anti-inflammatory, anti-swelling, anti-exudation, improving microcirculation, antioxidation, and antitumor activities [13]. Organic acids, such as chlorogenic acid and isochlorogenic acid, are the main active ingredients of Flos Lonicerae, which have antibacterial, anti-inflammatory, antiviral, hemostatic, and immune regulation activities [14]. 
Flavonoids, such as baicalin and wogonoside, are the main active ingredients of Radix Scutellariae. Baicalin has the effect of scavenging superoxide free radicals, and wogonoside plays a role in protecting the cardiovascular and cerebrovascular systems [15]. Calycosin-7glucoside, astraisoflavan-7-O- $\beta$-D-glucoside, and isomucronulatol 7-O-glucoside are the main active ingredients of Radix Astragali. They have the functions of strengthening the exterior, an antiperspirant, promoting diuresis and detumescence, improving body fluid and blood circulation, clearing stagnation and unblocking arthralgia, preventing soreness, and promoting muscle regeneration [16]. The structural formulas of the active ingredients in the above-mentioned medicinal herbs are shown in Figure 1.

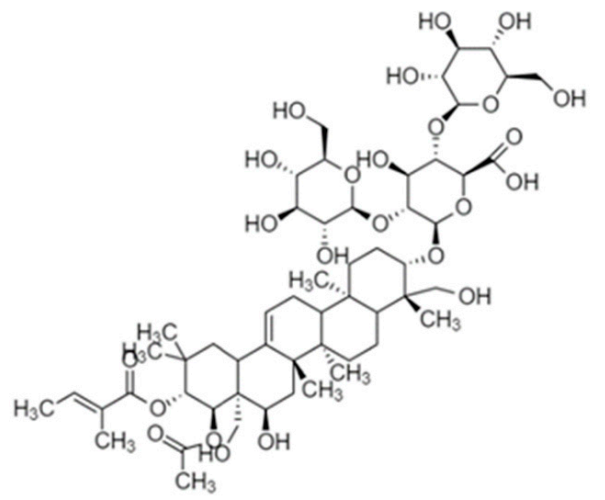

(a) Aescin A

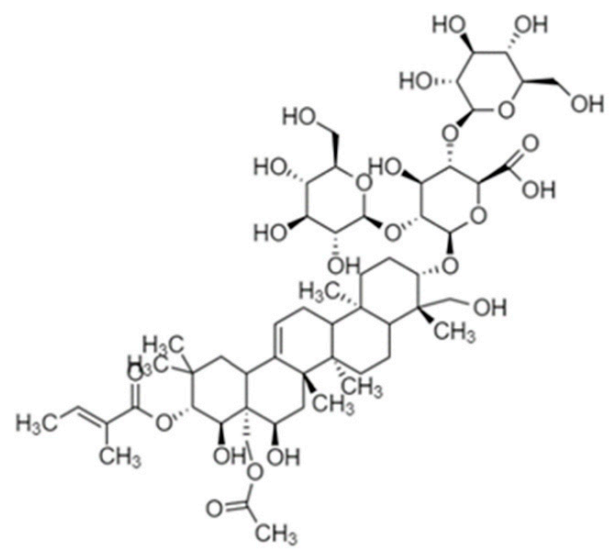

(c) Aescin C<smiles>O=C(/C=C/c1ccc(O)c(O)c1)O[C@H]1C[C@](O)(C(=O)O)C[C@H](O)[C@H]1O</smiles>

(e) Chlorogenic acid

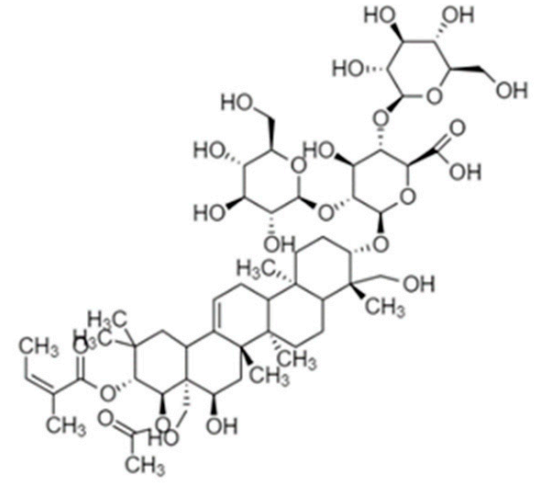

(b) Aescin B

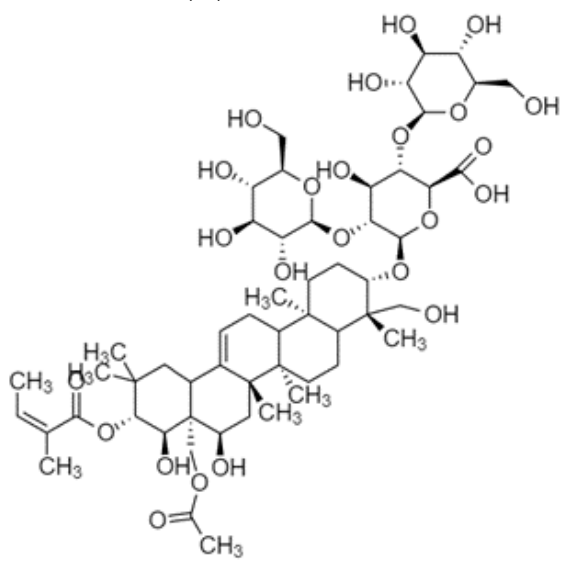

(d) Aescin D<smiles>O=C(/C=C/c1ccc(O)c(O)c1)O[C@@H]1C[C@@](O)(C(=O)O)C[C@H](O)[C@H]1O</smiles>

(f) Neochlorogenic acid

Figure 1. Cont. 
<smiles>O=C(/C=C/c1ccc(O)c(O)c1)O[C@H]1[C@@H](O)C[C@@](O)(C(=O)O)C[C@H]1O</smiles>

(g) Cryptochlorogenic acid<smiles>O=C(/C=C/c1ccc(O)c(O)c1)O[C@H]1[C@@H](O)C[C@@](O)(C(=O)O)C[C@H]1OC(=O)/C=C/c1ccc(O)c(O)c1</smiles>

(i) Isochlorogenic acid B<smiles>COc1ccc(C2COc3cc(OC4O[C@H](CO)[C@@H](O)[C@H](O)[C@H]4O)ccc3C2)c(O)c1OC</smiles>

(k) Isomucronulatol 7-O-glucoside<smiles>COc1ccc(-c2coc3cc(O[C@@H]4O[C@H](CO)[C@@H](O)[C@H](O)[C@H]4O)ccc3c2=O)cc1O</smiles>

(m) Calycosin-7-glucoside<smiles>O=C(O)[C@H]1O[C@@H](Oc2cc3oc(-c4ccccc4)cc(=O)c3c(O)c2O)[C@H](O)[C@@H](O)[C@H]1O</smiles>

(o) Baicalin<smiles>O=C(/C=C/c1ccc(O)c(O)c1)OC1C(O)[C@@H](OC(=O)/C=C/c2ccc(O)c(O)c2)CC1(O)C(=O)O</smiles>

(h) Isochlorogenic acid A<smiles>O=C(/C=C/c1ccc(O)c(O)c1)O[C@H]1C(O)C[C@@H](C(=O)O)C[C@H]1OC(=O)/C=C/c1ccc(O)c(O)c1</smiles>

(j) Isochlorogenic acid C<smiles>COc1ccc(C2COc3cc(O[C@@H]4O[C@H](CO)[C@@H](O)[C@H](O)C4O)ccc3C2)c(O)c1OC</smiles>

(1) Astraisoflavan-7-O- $\beta$-D-glucoside

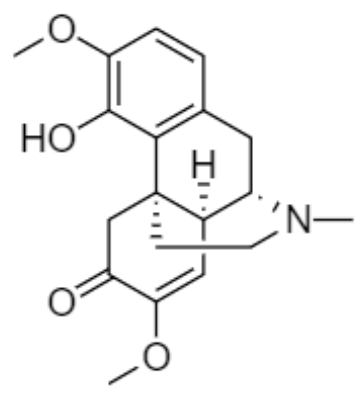

(n) Sinomenine<smiles>COc1c(O[C@@H]2O[C@H](C(=O)O)[C@@H](O)[C@H](O)[C@H]2O)cc(O)c2c(=O)cc(-c3ccccc3)oc12</smiles>

(p) Wogonoside

Figure 1. Structural formulas of the active ingredients in various medicinal herbs, (a) Aescin A; (b) Aescin B; (c) Aescin C; (d) Aescin D; (e) Chlorogenic acid; (f) Neochlorogenic acid; (g) Cryptochlorogenic acid; (h) Isochlorogenic acid A; (i) Isochlorogenic acid B; (j) Isochlorogenic acid C; (k) Isomucronulatol 7-O-glucoside; (l) Astraisoflavan-7-O- $\beta$-D-glucoside; (m) Calycosin-7-glucoside; (n) Sinomenine; (o) Baicalin; (p) Wogonoside. 
However, there are few reports on the $\mathrm{pK}_{\mathrm{a}}$ value and $D_{\mathrm{app}}$ of these active ingredients. In this work, the liquid-liquid equilibrium method was used to determine their $\mathrm{pK}_{\mathrm{a}}$ and $D_{\text {app }}$ data, which can be used to optimize the conditions for the extraction or analysis of these active ingredients.

\section{Material and Methods}

\subsection{Reagents and Materials}

Semen Aesculi was provided by the Harbin Sanctity Biological Pharmaceutical Co., Ltd. (Harbin, China). Flos Lonicerae was provided by Shanghai Kaibao Pharmaceutical Co., Ltd. (Shanghai, China). Caulis Sinomenii was purchased from Bozhou Yonggang Decoction Pieces Co., Ltd. (Bozhou, China). Radix Astragali was provided by Limin Pharmaceutical Factory of Livzon Group (Zhuhai, China). Radix Scutellariae was purchased from Gudun Chinese Medicine Clinic of Baozhentang (Hangzhou, China).

Methanol (purity $\geq 99.5 \%$, analytically pure), ethanol (purity $\geq 99.5 \%$, analytically pure), 1-butanol (purity $\geq 99.5 \%$, analytically pure), ethyl acetate (purity $\geq 99.5 \%$, analytically pure), and trichloromethane (purity $\geq 99.5 \%$, analytical purity) were purchased from the Sinopharm Chemical Reagent Co., Ltd. (Shanghai, China). Methyl isobutyl ketone (purity $\geq 99.5 \%$, analytical purity) and ethylenediamine (purity $\geq 99 \%$, chromatographic purity) were purchased from the Aladdin Chemical Reagent Co., Ltd. (Shanghai, China). Methanol (purity $\geq 99.9 \%$, chromatographic purity) was purchased from Merck Chemical Technology Co., Ltd. (Darmstadt, Germany). 1-Octanol (purity $\geq 99.5 \%$, analytical purity) was purchased from Shanghai Rhawn Chemical Technology Co., Ltd. (Shanghai, China). Sodium aescinate (33.5\% aescin A, 31.4\% aescin B, 17.8\% aescin C, 14.2\% aescin D) was purchased from the China Institute for Food and Drug Control. Sinomenine $(\geq 98 \%)$, neochlorogenic acid (>99\%), chlorogenic acid (>99\%), cryptochlorogenic acid (>99\%), isochlorogenic acid B (>99\%), isochlorogenic acid A (>99\%), isochlorogenic acid C (>99\%), isomucronulatol 7-O-glucoside (>99\%), astraisoflavan-7-O- $\beta$-D-glucoside (>99\%), calycosin-7-glucoside (>99\%), baicalin (>99\%), and wogonoside (>99\%) were purchased from the Shanghai Winherb Medical Technology Co., Ltd. (Shanghai, China).

\subsection{Preparation of Medicinal Material Extract}

\subsubsection{Preparation of Caulis Sinomenii Extract}

A total of $100.0 \mathrm{~g}$ of Caulis Sinomenii medicinal powder and a certain amount of $0.3 \mathrm{~mol} / \mathrm{L}$ of hydrochloric acid were placed into a beaker to swell for $1 \mathrm{~h}$. Then the mixture was transferred into a percolation tube to immerse for $12 \mathrm{~h}$. Finally, about $800 \mathrm{~mL}$ Caulis Sinomenii extract was obtained using a percolation process with $0.3 \mathrm{~mol} / \mathrm{L}$ of hydrochloric acid as the solvent solution at a flow rate of $4 \mathrm{~mL} / \mathrm{min}$.

\subsubsection{Preparation of Semen Aesculi Extract}

About $100.0 \mathrm{~g}$ of Semen Aesculi powder was extracted using $200.0 \mathrm{~g}$ of ether at room temperature with stirring for $3 \mathrm{~h}$. After filtration, $200.0 \mathrm{~g}$ of ether was added to the filter residue to continue the extraction with stirring for $3 \mathrm{~h}$. After filtration, $300.0 \mathrm{~g}$ of $60 \%$ ethanol was added to the filter residue to allow for extraction with stirring for $12 \mathrm{~h}$. After filtration, the filtrates were concentrated to an appropriate amount at $40{ }^{\circ} \mathrm{C}$. The Semen Aesculi extract was obtained via drying in a vacuum drying oven at $65^{\circ} \mathrm{C}$.

\subsubsection{Preparation of the Flos Lonicerae, Radix Scutellariae, and Radix Astragali Extracts}

A total of $40.0 \mathrm{~g}$ of Flos Lonicerae and $500 \mathrm{~mL}$ of water were mixed to allow for reflux extraction for $3 \mathrm{~h}$ at room temperature. The Flos Lonicerae extract was obtained after filtration. A total of $40.0 \mathrm{~g}$ of Radix Scutellariae and $1000 \mathrm{~mL}$ of water were mixed to allow for boiling extraction for $2 \mathrm{~h}$. The Radix Scutellariae extract was obtained after filtration. A total of $50.0 \mathrm{~g}$ of Radix Astragali and $800 \mathrm{~mL}$ of water were mixed and decocted for $4 \mathrm{~h}$. The Radix Astragali extract was obtained after filtration. 


\subsection{Liquid-Liquid Equilibrium Extraction Experiment}

2.3.1. Liquid-Liquid Equilibrium Experiment of Caulis Sinomenii

About $30 \mathrm{~g}$ of Caulis Sinomenii extract and $30 \mathrm{~g}$ of organic extractant were placed into each Erlenmeyer flask with different amounts of $\mathrm{NaOH}$ solution being added to adjust the $\mathrm{pH}$ value, which was measured using a $\mathrm{pH}$ meter (S40, Mettler-Toledo Instruments Co., Ltd., Shanghai, China). Erlenmeyer flasks were placed in a constant temperature water bath oscillator (DSHZ-300, Taicang City Experimental Equipment Factory, Taicang, China) at $30^{\circ} \mathrm{C}$ and shaken at $110 \mathrm{rpm}$ for $12 \mathrm{~h}$. Then, the organic and aqueous phases in the mixed solution were separated using a centrifuge (5804R, Eppendorf, Shanghai, China) at $4200 \mathrm{rpm}$ for $15 \mathrm{~min}$. The $\mathrm{pH}$ value of the aqueous phase was then measured. The aqueous phase was diluted with $0.3 \mathrm{~mol} / \mathrm{L}$ of hydrochloric acid and the organic phase was diluted with methanol. After filtering with a $0.22 \mu \mathrm{m}$ microporous membrane (Fitmax Syringe Filter $13 \mathrm{~mm} 0.22 \mu \mathrm{m}$ Nylon 100/pk, Dikma, Beijing, China), the subsequent filtrate was taken out for high-performance liquid chromatography (HPLC) (FL5090, Zhejiang Fuli Analytical Instrument Co., Ltd., Taizhou, China) analysis. Experiments were carried out in different extraction systems, where the experimental conditions are shown in Table 1.

Table 1. Liquid-liquid equilibrium extraction system.

\begin{tabular}{cccc}
\hline Number & Medicinal Extracts & Organic Extractant & Equilibrium Temperature \\
\hline 1 & & Trichloromethane & $30{ }^{\circ} \mathrm{C}$ \\
2 & Caulis Sinomenii & 1-Butanol & $30{ }^{\circ} \mathrm{C}$ \\
3 & & Methyl isobutyl ketone & $30^{\circ} \mathrm{C}$ \\
4 & & 1-Octanol & $30^{\circ} \mathrm{C}$ \\
\hline 5 & Semen Aesculi & 1-Butanol & $30^{\circ} \mathrm{C}$ \\
6 & Flos Lonicerae & 1-Octanol & $30^{\circ} \mathrm{C}$ \\
7 & Radix Scutellariae & 1-Octanol & $30^{\circ} \mathrm{C}$ \\
8 & Radix Astragali & 1-Octanol & $30^{\circ} \mathrm{C}$ \\
\hline
\end{tabular}

\subsubsection{Liquid-Liquid Equilibrium Experiment Using Semen Aesculi}

About $0.25 \mathrm{~g}$ of Semen Aesculi extract, $30.0 \mathrm{~g}$ of water, and $30 \mathrm{~g}$ of 1-butanol were added to each Erlenmeyer flask with different amounts of $1 \%$ hydrochloric acid and $1 \%$ $\mathrm{NaOH}$ solution added to adjust the $\mathrm{pH}$ value. Then, Erlenmeyer flasks were placed in a constant-temperature water bath oscillator at $30^{\circ} \mathrm{C}$ and shaken at $140 \mathrm{rpm}$ for $12 \mathrm{~h}$. After centrifugation, the organic and aqueous phases in the mixture were separated, and the $\mathrm{pH}$ value of the aqueous phase was measured. The two phases were diluted with methanol separately. These solutions were filtered through a $0.22 \mu \mathrm{m}$ filter membrane and analyzed using HPLC.

\subsubsection{Liquid-Liquid Equilibrium Experiment Using Flos Lonicerae}

A total of $15 \mathrm{~mL}$ of Flos Lonicerae extract and $10 \mathrm{~mL}$ of 1-octanol were placed into each Erlenmeyer flask. Different amounts of 1\% hydrochloric acid solution were used to adjust the $\mathrm{pH}$ value. Then, Erlenmeyer flasks were placed in a constant temperature water bath oscillator at $30^{\circ} \mathrm{C}$ and shaken at $140 \mathrm{rpm}$ for $12 \mathrm{~h}$. The solution was centrifuged at $3000 \mathrm{rpm}$ for $20 \mathrm{~min}$ to separate the two-phase solution, and the $\mathrm{pH}$ value of the aqueous phase was measured. The concentrations of the neochlorogenic acid, chlorogenic acid, cryptochlorogenic acid, isochlorogenic acid $\mathrm{B}$, isochlorogenic acid $\mathrm{A}$, and isochlorogenic acid $\mathrm{C}$ in each phase were determined using HPLC (1100, Agilent Technology, Beijing, China).

\subsubsection{Liquid-Liquid Equilibrium Experiment Using Radix Scutellariae}

A total of $15 \mathrm{~mL}$ of the Radix Scutellariae extract and $10 \mathrm{~mL}$ of 1-octanol were added to each Erlenmeyer flask, and different amounts of $1 \%$ hydrochloric acid solution were used to adjust the $\mathrm{pH}$ value. Then, Erlenmeyer flasks were shaken for $10 \mathrm{~h}$ at $140 \mathrm{rpm}$ at $30^{\circ} \mathrm{C}$. The aqueous and organic phases were separated via centrifugation at $3000 \mathrm{rpm}$ for $20 \mathrm{~min}$. 
After being filtered with a $0.22 \mu \mathrm{m}$ microporous membrane, the solution was analyzed using HPLC to determine the concentrations of baicalin and wogonoside in each phase.

\subsubsection{Liquid-Liquid Equilibrium Experiment Using Radix Astragali}

A total of $15 \mathrm{~mL}$ of Radix Astragali extract and $10 \mathrm{~mL}$ of 1 -octanol were added to each Erlenmeyer flask. Different amounts of $1 \%$ hydrochloric acid solution or $0.02 \mathrm{~g} / \mathrm{mL}$ of $\mathrm{NaOH}$ solution were used to adjust the $\mathrm{pH}$ value. The Erlenmeyer flasks were shaken for $10 \mathrm{~h}$ at $140 \mathrm{rpm}$ in a $30{ }^{\circ} \mathrm{C}$ constant-temperature oscillator. The aqueous and organic phases were separated via centrifugation at $3000 \mathrm{rpm}$ for $20 \mathrm{~min}$. After being filtered with a $0.22 \mu \mathrm{m}$ microporous membrane, the solution was analyzed using HPLC to determine the concentrations of isomucronulatol 7-O-glucoside, astraisoflavan-7-O- $\beta$-D-glucoside, and calycosin-7-glucoside in each phase.

\subsection{Analysis Method}

\subsubsection{Analysis Method of Sinomenine in Caulis Sinomenii}

The method was performed on a Fuli HPLC system using an Agilent ZORBAX SBC18 column $(250 \mathrm{~mm} \times 4.6 \mathrm{~mm}, 5 \mu \mathrm{m})$ at $25{ }^{\circ} \mathrm{C}$. The mobile phase consisted of $0.25 \%$ ethylenediamine-water (A) and $0.25 \%$ ethylenediamine-methanol (B) using $(50 / 50, v / v)$ gradient program. The flow rate was $1 \mathrm{~mL} / \mathrm{min}$ and the volume of the sample injection was $10 \mu \mathrm{L}$. The detector wavelength was set to $262 \mathrm{~nm}$. The detection time was $30 \mathrm{~min}$. A typical chromatogram of the Caulis Sinomenii system is shown in Figure A1 in the Appendix A.

\subsubsection{Analysis Method of Aescins in Semen Aesculi}

The concentrations of aescin A, aescin B, aescin C, and aescin D were determined using HPLC analysis according to the method published by Cao et al. [17]. The method was performed on a Fuli HPLC system using an Agilent ZORBAX SB-C18 column $(250 \mathrm{~mm} \times 4.6 \mathrm{~mm}$, $5 \mu \mathrm{m})$ at $35{ }^{\circ} \mathrm{C}$. The mobile phase consisted of $0.2 \%$ phosphoric acid-water $(\mathrm{A})$ and acetonitrile (B) using a 63/37 (v/v) gradient program. The flow rate was $1 \mathrm{~mL} / \mathrm{min}$, and the injection volume was $10 \mu \mathrm{L}$. The detector wavelength was set to $220 \mathrm{~nm}$. The detection time was $30 \mathrm{~min}$. A typical chromatogram of Semen Aesculi is shown in Figure A2 in the Appendix A.

\subsubsection{Analysis Method of Phenolic Acids in Flos Lonicerae}

The concentrations of chlorogenic acid, neochlorogenic acid, isochlorogenic acids A, $B$, and C, and cryptochlorogenic acid were determined using HPLC analysis according to the method published by Wang et al. [18]. The method was performed on an Agilent HPLC system using an Agilent ZORBAX SB-C18 column $(250 \mathrm{~mm} \times 4.6 \mathrm{~mm}, 5 \mu \mathrm{m})$ at $30{ }^{\circ} \mathrm{C}$. The mobile phase consisted of $0.1 \%$ phosphoric acid-water (A) and acetonitrile (B) using the following gradient program: $8-10 \%$ B from 0 to $10 \mathrm{~min}, 10-15 \%$ B from 10 to $20 \mathrm{~min}, 15-15 \%$ B from 20 to $30 \mathrm{~min}, 15-25 \%$ B from 30 to $40 \mathrm{~min}$, and $25-100 \%$ B from 40 to $60 \mathrm{~min}$. The flow rate was $1 \mathrm{~mL} / \mathrm{min}$ and the volume of the sample injection was $10 \mu \mathrm{L}$. The detector wavelength was set to $325 \mathrm{~nm}$. The detection time was $30 \mathrm{~min}$. A typical chromatogram of Flos Lonicerae is shown in Figure A3 in the Appendix A.

\subsubsection{Analysis Method of Flavonoids in Radix Scutellariae}

The concentrations of baicalin and wogonoside were determined using HPLC analysis according to the method published by Zhu et al. [19]. The method was performed on an Agilent HPLC system using an Agilent ZORBAX SB-C18 column (250 mm $\times 4.6 \mathrm{~mm}, 5 \mu \mathrm{m})$ at $25{ }^{\circ} \mathrm{C}$. The mobile phase consisted of $0.2 \%$ phosphoric acid-water(A) and methanol (B) using the following gradient program: $45-45 \%$ B from 0 to $10 \mathrm{~min}$ and $45-70 \%$ B from 10 to $55 \mathrm{~min}$. The flow rate was $1 \mathrm{~mL} / \mathrm{min}$ and the injection volume was $10 \mu \mathrm{L}$. The detector wavelength was set to $274 \mathrm{~nm}$. The detection time was $30 \mathrm{~min}$. A typical chromatogram of Radix Scutellariae is shown in Figure A4 in the Appendix A. 


\subsubsection{Analysis Method of Flavonoids in Radix Astragali}

The concentrations of calycosin-7-glucoside, astraisoflavan-7-O- $\beta$-D-glucoside, and isomucronulatol 7-O-glucoside were determined using HPLC analysis according to the method published by Chen et al. [20]. The method was performed on an Agilent HPLC system using a Diamonsil C18 column $(250 \mathrm{~mm} \times 4.6 \mathrm{~mm}, 5 \mu \mathrm{m})$ at $35^{\circ} \mathrm{C}$. The mobile phase consisted of $0.05 \%$ formic acid-water (A) and acetonitrile (B) using the following gradient program: $15-29 \%$ B from 0 to $40 \mathrm{~min}, 29-40 \%$ B from 40 to $50 \mathrm{~min}, 40-40 \%$ B from 50 to $60 \mathrm{~min}$, and $40-90 \%$ B from 60 to $70 \mathrm{~min}$. The flow rate was $1 \mathrm{~mL} / \mathrm{min}$ and the volume of the sample injection was $10 \mu \mathrm{L}$. The detector wavelength was set to $210 \mathrm{~nm}$. The detection time was $30 \mathrm{~min}$. A typical chromatogram of Radix Astragali is shown in Figure $\mathrm{A} 5$ in the Appendix A.

\subsection{Data Processing}

2.5.1. $\mathrm{pK}_{\mathrm{a}}$ Fitting of the Active Ingredients in Semen Aesculi, Flos Lonicerae, Radix Scutellariae, and Radix Astragali

For active ingredients in Semen Aesculi, Flos Lonicerae, Radix Scutellariae, and Radix Astragali, the nonlinear fitting formulas for $\mathrm{pK}_{\mathrm{a}}$ and $D_{\text {app }}$ derived by Gong et al. [10] were used to fit the $\mathrm{pK}_{\mathrm{a}}$, as shown in Formulas (1)-(3).

$$
D_{\text {app }}=\frac{C_{\text {org }}}{C_{\mathrm{aq}}},
$$

where $D_{\text {app }}$ is the apparent distribution coefficient, $C(\mathrm{mg} / \mathrm{L})$ refers to the concentration of the target component, and the subscripts org and aq refer to the organic phase and the water phase, respectively.

$$
D_{\text {app }}=\frac{D_{0}+D_{1} 10^{\mathrm{pH}-\mathrm{pK}_{\mathrm{a}}}}{1+10^{\mathrm{pH}-\mathrm{pK}_{\mathrm{a}}}},
$$

where $D_{0}$ is the distribution coefficient of the molecule, and $D_{1}$ is the distribution coefficient of the first-order dissociated ion. When fitting, the logarithms of both sides of the formula were taken to get the following formula:

$$
\lg \left(D_{\mathrm{app}}\right)=\lg \left(\frac{10^{d_{0}}+10^{d_{1}+\mathrm{pH}-\mathrm{pK}_{\mathrm{a}}}}{1+10^{\mathrm{pH}-\mathrm{pK}_{\mathrm{a}}}}\right)
$$

where $d_{0}$ and $d_{1}$ are the base $10 \operatorname{logarithms}$ of $D_{0}$ and $D_{1}$, respectively.

\subsection{2. $\mathrm{pK}_{\mathrm{a}}$ Fitting of Sinomenine}

Sinomenine is an alkaloid and its structural formula is shown in Figure 1. It shows that the dissociable groups of sinomenine are mainly tertiary amino groups and phenolic hydroxyl groups. When $0.3 \mathrm{~mol} / \mathrm{L}$ of hydrochloric acid was used to extract Caulis Sinomenii, the tertiary amino group on sinomenine reacted with hydrochloric acid to form sinomenine hydrochloride salt. When exposed to alkali, the sinomenine hydrochloride salt removes the hydrochloric acid to generate sinomenine molecules. The reaction equation is shown in Scheme 1.
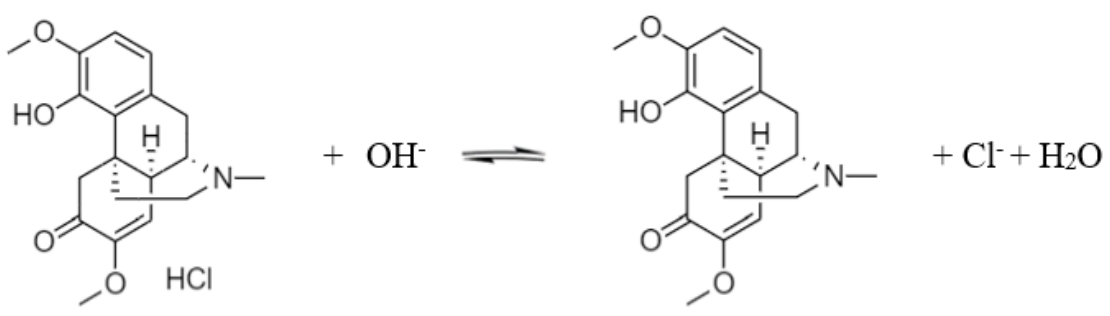

Scheme 1. Dissociation of sinomenine hydrochloride. 
With further exposure to an alkali, the phenolic hydroxyl group on the sinomenine molecule ionizes to form a salt. The sodium salt of sinomenine is soluble in water. The reaction equation is shown in Scheme 2.

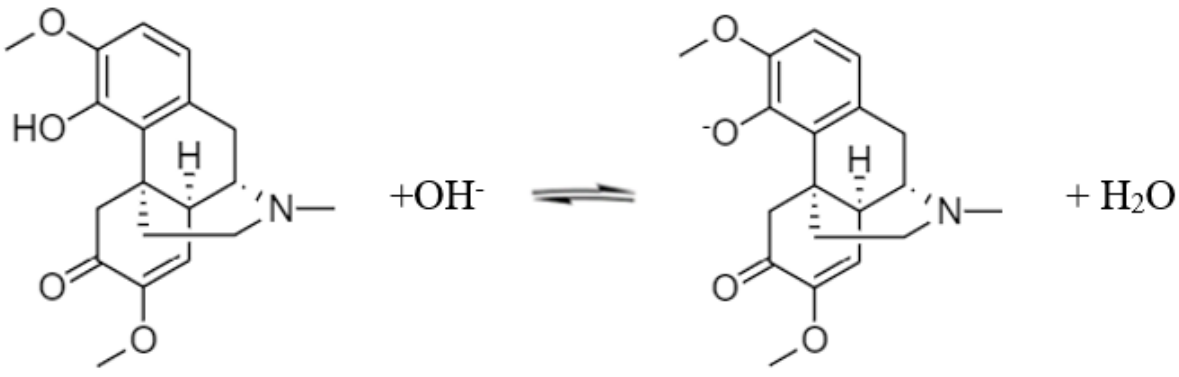

Scheme 2. Dissociation of sinomenine.

Sinomenine hydrochloride can be regarded as a dibasic acid when the two $\mathrm{pK}_{\mathrm{a}}$ values of sinomenine were fitted simultaneously. The hydrochloric acid is completely removed during the first dissociation, and the phenolic hydroxyl group is ionized during the second dissociation. Based on Gong et al. [10], Formula (4) was used for the data fitting:

$$
D_{\text {app }}=\frac{D_{0} 10^{\mathrm{pK}_{\mathrm{a}, 1}-\mathrm{pH}}+D_{1}+D_{2} 10^{\mathrm{pH}-\mathrm{pK}_{\mathrm{a}, 2}}}{10^{\mathrm{pK}_{\mathrm{a}, 1}-\mathrm{pH}}+1+10^{\mathrm{pH}-\mathrm{pK}_{\mathrm{a}, 2}}},
$$

where $D_{2}$ is the distribution coefficient of sinomenine after the secondary dissociation, $\mathrm{pK}_{\mathrm{a}, 1}$ is the first dissociated $\mathrm{pK}_{\mathrm{a}}$ (the $\mathrm{pK}_{\mathrm{a}}$ of sinomenine hydrochloride), and $\mathrm{pK}_{\mathrm{a}, 2}$ is the $\mathrm{pK}_{\mathrm{a}}$ of the secondary dissociation (the $\mathrm{pK}_{\mathrm{a}}$ of the phenolic hydroxyl group). When fitting, the logarithm of both sides of the formula was also taken to obtain Formula (5):

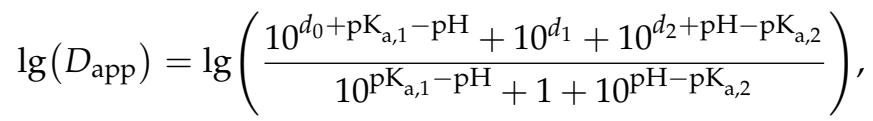

where $d_{2}$ is the base 10 logarithm of $D_{2}$. If a value of $d_{0}, d_{1}$, or $d_{2}$ was less than -20 , the corresponding distribution coefficient was considered to be extremely small. In order to facilitate the fitting of other parameters, the value of the extremely small $d_{0}, d_{1}$, or $d_{2}$ was set to -20 .

\section{Results and Discussion}

In this work, the extracts of the medicinal herbs were prepared and extracted with organic solvents. After reaching liquid-liquid equilibrium, the concentrations of the active ingredients in the two phases were determined. The $D_{\text {app }}$ values were calculated and fitted using Formula (3) or (5) to obtain the $\mathrm{pK}_{\mathrm{a}}$ value.

\section{1. $D_{\text {app }}$ and $p K_{a}$ of Sinomenine}

The $D_{\text {app }}$ of sinomenine at different $\mathrm{pH}$ values in the 1-butanol-water, trichloromethanewater, methyl isobutyl ketone-water, and 1-octanol-water systems were found, as seen in Table A1. The results are shown in Figure 2.

As shown in Figure 2, when the $\mathrm{pH}$ value of the system was less than 10 in the four liquid-liquid equilibrium systems, the $D_{\text {app }}$ value increased as the $\mathrm{pH}$ value increased. When the $\mathrm{pH}$ value of the system was greater than 10 , the $D_{\text {app }}$ value decreased as the $\mathrm{pH}$ value increased. When the $\mathrm{pH}$ value was low, such as less than the $\mathrm{pK}_{\mathrm{a}}$ of the amine group, the proportion of sinomenine in molecular form increased as the $\mathrm{pH}$ value increased. Therefore, the $D_{\text {app }}$ value of the liquid-liquid extraction was observed to increase. When the $\mathrm{pH}$ value increased to be higher than the $\mathrm{pK}_{\mathrm{a}}$ of phenolic hydroxyl ionization, the proportion of sinomenine in the salt form increased. Therefore, the $D_{\text {app }}$ value of sinomenine 
decreased. The maximum $D_{\text {app }}$ of sinomenine in 1-butanol-water system was more than 60 . The maximum $D_{\text {app }}$ in trichloromethane-water system was more than 500 , indicating that the extraction capacity of trichloromethane was very large. The maximum $D_{\text {app }}$ in methyl isobutyl ketone-water system was less than 1.1, indicating that the extraction capacity of the methyl isobutyl ketone was small. The maximum $D_{\text {app }}$ in 1-octanol-water system was about 40 , which was a little lower than that of the 1-butanol system.

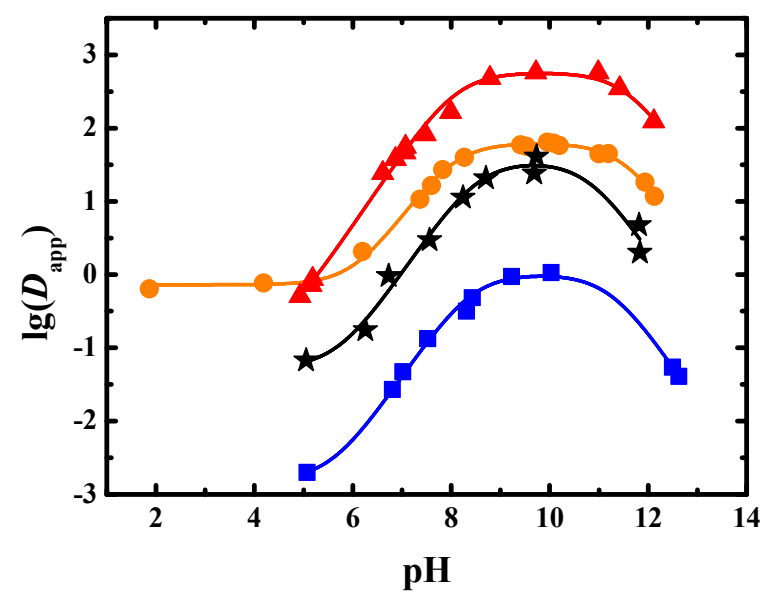

Figure 2. Experimental and fitted results of $D_{\text {app }}$ of sinomenine obtained in four extraction systems ( $\bullet$ : 1-butanol, $\mathbf{\Delta}$ : trichloromethane, $\mathbf{\square}$ : methyl isobutyl ketone, $\star$ : 1-octanol, solid line: fitted results).

The experimental results were fitted using Origin software (2018, OriginLab, MA, USA) and are shown in Table 2 and Figure 2. The distribution coefficient of sinomenine salt after ionization of the phenolic hydroxyl group was too small; thus, $d_{2}$ was set to -20 for the fitting. It can be seen from Table 2 that the $R^{2}$ adj values that were obtained by fitting the data from the four extraction systems of 1-butanol-water, trichloromethane-water, methyl isobutyl ketone-water, and 1-octanol-water were 0.996, 0.992, 0.992, and 0.969, respectively, which showed that the fitting results were in good agreement with the measured values. From the fitting results, the $\mathrm{pK}_{\mathrm{a}, 1}$ values of sinomenine conjugate acid were 8.01, 8.10, 8.40 , and 8.53 , respectively. The $\mathrm{pK}_{\mathrm{a}, 2}$ values of the phenolic hydroxyl dissociation of sinomenine were 11.52,11.59, 11.25, and 10.81, respectively. The distribution coefficients of the sinomenine molecules in the 1-butanol-water, trichloromethane-water, methyl isobutyl ketone-water, and 1-octanol-water systems were 62.4, 575, 1.01, and 35.2, respectively. The distribution coefficients of sinomenine hydrochloride in the above four systems were $7.26 \times 10^{-1}, 1.20 \times 10^{-1}, 1.53 \times 10^{-3}$, and $5.32 \times 10^{-2}$, respectively, indicating that the four solvents had poor extraction capacities for sinomenine hydrochloride salt in water. Because 1 -octanol was applied as the extractant, the $\log P$ values of sinomenine and sinomenine hydrochloride were 1.55 and -1.27 , respectively.

Table 2. The $\mathrm{pK}_{\mathrm{a}}$ fitting results for sinomenine.

\begin{tabular}{ccccc}
\hline Variable & 1-Butanol & Trichloromethane & Methyl Isobutyl Ketone & 1-Octanol \\
\hline$d_{0}$ & $-0.14 \pm 0.03$ & $-0.92 \pm 0.35$ & $-2.81 \pm 0.10$ & $-1.27 \pm 0.20$ \\
$d_{1}$ & $1.80 \pm 0.02$ & $2.76 \pm 0.06$ & $0.01 \pm 0.06$ & $1.55 \pm 0.12$ \\
$d_{2}$ & -20 & -20 & -20 & -20 \\
$\mathrm{pK}_{\mathrm{a}, 1}$ & $8.01 \pm 0.04$ & $8.10 \pm 0.08$ & $8.40 \pm 0.08$ & $8.53 \pm 0.18$ \\
$\mathrm{pK}_{\mathrm{a}, 2}$ & $11.52 \pm 0.05$ & $11.59 \pm 0.15$ & $11.25 \pm 0.08$ & $10.81 \pm 0.19$ \\
$R^{2}{ }_{\text {adj }}$ & 0.996 & 0.992 & 0.992 & 0.969 \\
\hline
\end{tabular}




\section{2. $D_{a p p}$ and $p K_{a}$ of Aescins}

The liquid-liquid equilibrium experiments of the Semen Aesculi extract were carried out with 1-butanol as the extractant. The experimental results of $D_{\text {app }}$ of aescins are shown in Figure 3 and Table A2.

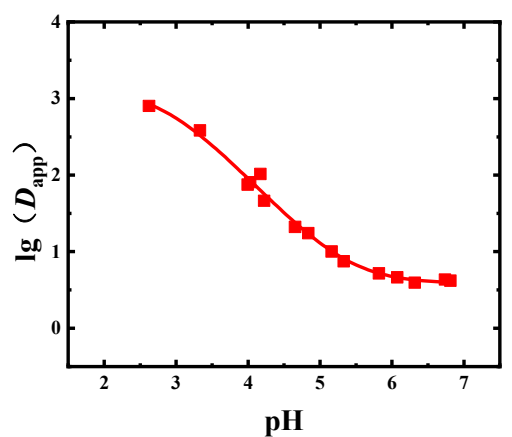

(a) Aescin A

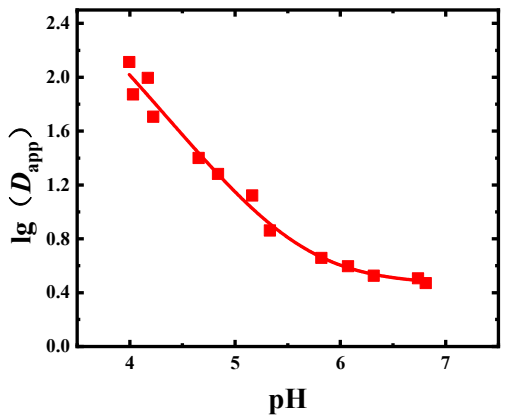

(c) Aescin C

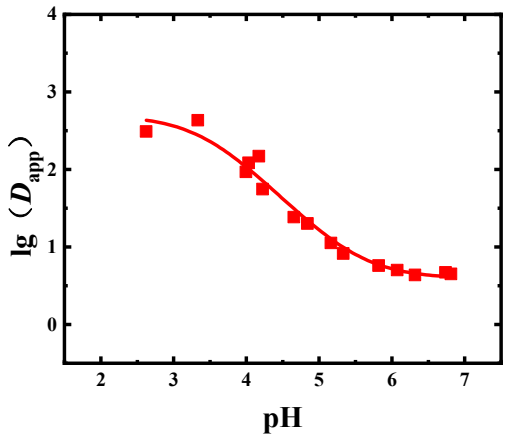

(b) Aescin B

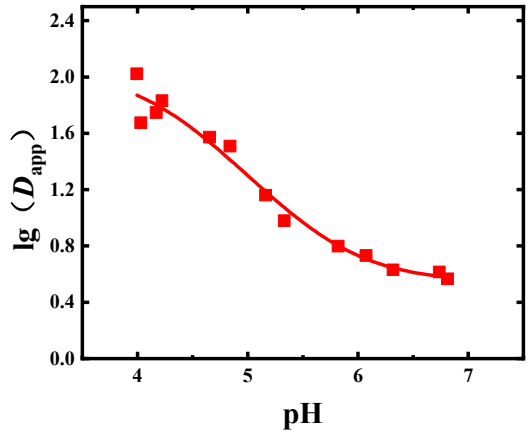

(d) Aescin D

Figure 3. Experimental and fitted results for the $D_{\text {app }}$ of the four aescins obtained in the 1-butanol system (ם: experimental results, solid line: fitted results); (a) Aescin A; (b) Aescin B; (c) Aescin C; (d) Aescin D.

In the 1-butanol equilibrium system, the change trends of the $D_{\text {app }}$ values of the four aescins were roughly the same. When the $\mathrm{pH}$ value increased, the $D_{\text {app }}$ value gradually decreased. The $D_{\text {app }}$ value changed rapidly between $\mathrm{pH} 3.0$ and 5.0. The data obtained in the 1-butanol system was fitted, and the initial values of $d_{0}, d_{1}$, and $\mathrm{pK}_{\mathrm{a}}$ were adjusted to make the fitted curve better coincide with the actual data points. The fitting results are shown in Table 3 and Figure 3.

Table 3. The $\mathrm{pK}_{\mathrm{a}}$ fitting results of aescins.

\begin{tabular}{ccccc}
\hline Aescin & $\boldsymbol{d}_{\mathbf{0}}$ & $\boldsymbol{d}_{\mathbf{1}}$ & $\mathbf{p K}_{\mathbf{a}}$ & $\boldsymbol{R}_{\mathbf{a d j}}$ \\
\hline Aescin A & $3.14 \pm 0.13$ & $0.58 \pm 0.04$ & $2.83 \pm 0.14$ & 0.989 \\
Aescin B & $2.70 \pm 0.13$ & $0.59 \pm 0.07$ & $3.42 \pm 0.16$ & 0.970 \\
Aescin C & $2.96 \pm 0.78$ & $0.46 \pm 0.05$ & $3.10 \pm 0.84$ & 0.982 \\
Aescin D & $2.06 \pm 0.11$ & $0.54 \pm 0.06$ & $4.24 \pm 0.18$ & 0.970 \\
\hline
\end{tabular}

It can be seen from Table 3 that the $D_{\text {app }}$ results of aescins $A, B, C$, and D in the 1-butanol system were fitted well, with $R^{2}$ values greater than 0.97 . The value of $d_{0}$ was higher than that of $d_{1}$ because the solubility of the molecules in the organic phase was higher than that of the ions. Overall, the $d_{0}$ values of the four ingredients were greater than 2.00, that is, the distribution coefficients of the molecular forms of the aescins were greater than 100 . The $d_{1}$ values were in the range of $0-1$, which means that the distribution 
coefficients of the ionic form of the aescins were in the range of 1-10. This shows that the solubility of the aescins in the 1-butanol phase was quite large. In the 1-butanol system, the calibrated $\mathrm{pK}_{\mathrm{a}}$ values of aescins A, B, C, and D were 2.83, 3.42, 3.10, and 4.24, respectively.

\section{3. $D_{a p p}$ and $p K_{a}$ of the Phenolic Acids in Flos Lonicerae}

In the liquid-liquid equilibrium experiments using the Flos Lonicerae extract, 1octanol was the extractant. The $D_{\text {app }}$ values of neochlorogenic acid, chlorogenic acid, cryptochlorogenic acid, isochlorogenic acid A, isochlorogenic acid B, and isochlorogenic acid $\mathrm{C}$ at different $\mathrm{pH}$ values are shown in Figure 4 and Table A3. It can be seen from Figure 4 that as the $\mathrm{pH}$ value decreased, the $D_{\text {app }}$ value increased. The $D_{\text {app }}$ value of isochlorogenic acid C was the largest, while the $D_{\text {app }}$ value of neochlorogenic acid was the lowest at the same $\mathrm{pH}$ value. The $D_{\text {app }}$ values of isochlorogenic acids $\mathrm{A}, \mathrm{B}$, and $\mathrm{C}$ in the 1-octanol system could reach more than 100 . The $D_{\text {app }}$ values of neochlorogenic acid, chlorogenic acid, and cryptochlorogenic acid were below 10.

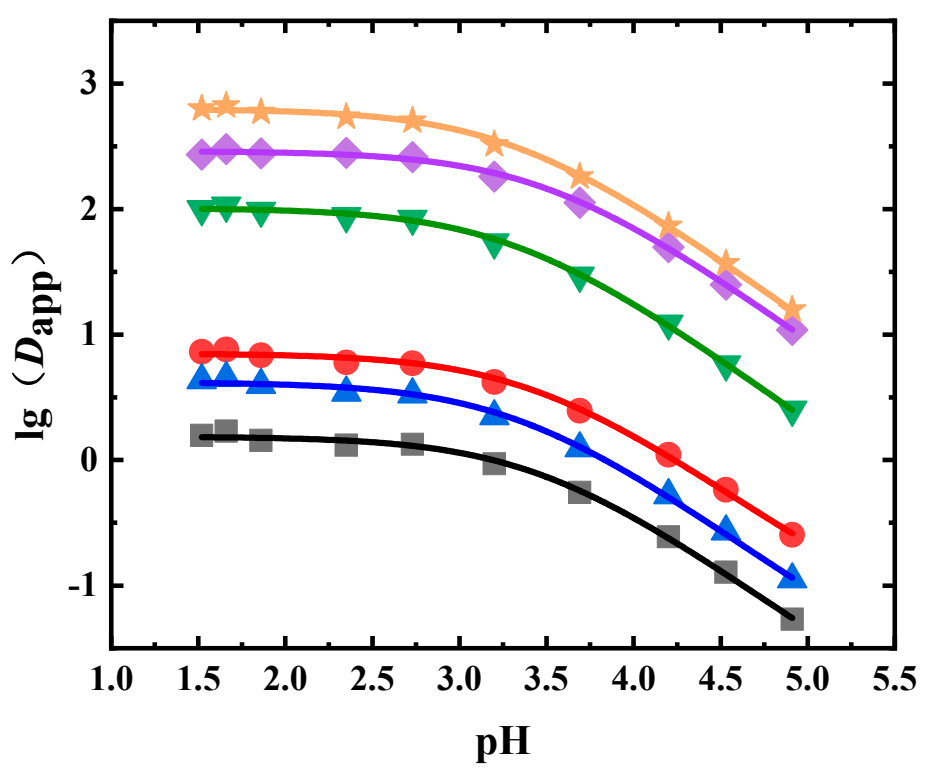

Figure 4. Experimental and fitted results of $D_{\text {app }}$ of six phenolic acids in Flos Lonicerae ( $\mathbf{\square}$ : neochlorogenic acid, $\bullet$ : chlorogenic acid, $\mathbf{\Delta}$ : cryptochlorogenic acid, $\bullet$ : isochlorogenic acid $A, \mathbf{v}$ : isochlorogenic acid $B, \star$ : isochlorogenic acid $C$, solid line: fitted results).

The obtained $D_{\text {app }}$ values were fitted, where the fitting results are shown in Table 4 . It can be seen from Table 4 and Figure 4 that the fitting results agreed well with the experimental results, with $R^{2}$ values higher than 0.99 . The $\mathrm{pK}_{\mathrm{a}}$ values of all six phenolic acids were between 3.3 and 3.5. The $\log P$ values of chlorogenic acid, neochlorogenic acid, cryptochlorogenic acid, isochlorogenic acid A, isochlorogenic acid B, and isochlorogenic acid $C$ were $0.85,0.19,0.62,2.46,2.01$, and 2.80 , respectively.

Table 4. The $\mathrm{pK}_{\mathrm{a}}$ fitting results of six phenolic acid ingredients of Flos Lonicerae.

\begin{tabular}{ccccc}
\hline Phenolic Acid & $\boldsymbol{d}_{\mathbf{0}}$ & $\boldsymbol{d}_{\mathbf{1}}$ & $\mathbf{p K}_{\mathbf{a}}$ & $\boldsymbol{R}_{\mathbf{a d j}}$ \\
\hline Chlorogenic acid & $0.85 \pm 0.01$ & $-1.50 \pm 0.34$ & $3.44 \pm 0.03$ & 0.997 \\
Neochlorogenic acid & $0.19 \pm 0.01$ & $-2.57 \pm 0.96$ & $3.46 \pm 0.04$ & 0.997 \\
Cryptochlorogenic acid & $0.62 \pm 0.01$ & $-2.08 \pm 0.63$ & $3.33 \pm 0.04$ & 0.997 \\
Isochlorogenic acid A & $2.46 \pm 0.01$ & -20 & $3.50 \pm 0.02$ & 0.999 \\
Isochlorogenic acid B & $2.01 \pm 0.01$ & -20 & $3.31 \pm 0.02$ & 0.999 \\
Isochlorogenic acid C & $2.80 \pm 0.01$ & -20 & $3.31 \pm 0.02$ & 0.999 \\
\hline
\end{tabular}




\section{4. $D_{a p p}$ and $p K_{a}$ of Flavonoids in Radix Scutellariae}

1-Octanol was the extractant in the liquid-liquid equilibrium extraction experiment using the Radix Scutellariae extract. The $D_{\text {app }}$ values of wogonoside and baicalin under different $\mathrm{pH}$ values are shown in Figure 5 and Table A4. It can be seen that the $D_{\text {app }}$ changing trends of baicalin and wogonoside were very similar. As the $\mathrm{pH}$ value increased, the $D_{\text {app }}$ values of wogonoside and baicalin decreased. The $D_{\text {app }}$ value of wogonoside was higher than that of baicalin, which means that the extraction capacity of wogonoside in 1-octanol was larger.

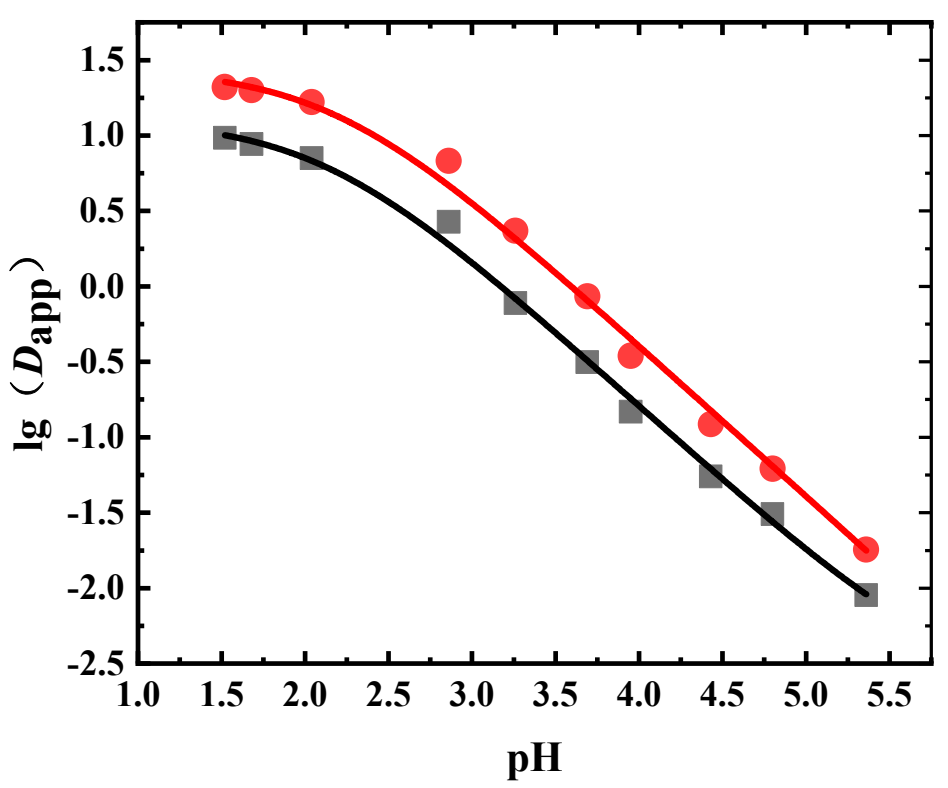

Figure 5. Experimental and fitted results of the $D_{\text {app }}$ of flavonoids in Radix Scutellariae ( $\bullet$ : wogonoside, $\mathbf{\square}$ : baicalin, solid line: fitted results).

The obtained $D_{\text {app }}$ values were fitted, where the fitting results are shown in Table 5 and Figure 5. From Table 5, it can be seen that the fitting results agreed well with experimental results, with $R^{2}$ values greater than 0.99 . Since these two flavonoids contain carboxyl groups, the $\mathrm{pK}_{\mathrm{a}}$ values obtained were both around 2.1. The $\log P$ values of baicalin and wogonoside were 1.10 and 1.44 , respectively.

Table 5. The $\mathrm{pK}_{\mathrm{a}}$ fitting results of flavonoids in Radix Scutellariae.

\begin{tabular}{ccccc}
\hline Flavanoid & $\boldsymbol{d}_{\mathbf{0}}$ & $\boldsymbol{d}_{\mathbf{1}}$ & $\mathbf{p K}_{\mathbf{a}}$ & $\boldsymbol{R}_{\mathbf{a d j}}$ \\
\hline Baicalin & $1.10 \pm 0.06$ & $-2.68 \pm 0.35$ & $2.10 \pm 0.08$ & 0.996 \\
Wogonoside & $1.44 \pm 0.07$ & -20 & $2.17 \pm 0.08$ & 0.997 \\
\hline
\end{tabular}

\section{5. $D_{a p p}$ and $p K_{a}$ of Glycosides in Radix Astragali}

1-Octanol was the extractant in the liquid-liquid equilibrium extraction experiment using the Radix Astragali extract. The $D_{\text {app }}$ values of astraisoflavan-7-O- $\beta$-D-glucoside, isomucronulatol 7-O-glucoside, and calycosin-7-glucoside at different $\mathrm{pH}$ values are shown in Figure 6 and Table A5. It can be seen that the $D_{\text {app }}$ values of astraisoflavan-7-O- $\beta$-Dglucoside and isomucronulatol 7-O-glucoside were less than 10 , but the $D_{\text {app }}$ values of calycosin-7-glucoside were less than 1 . When the $\mathrm{pH}$ value was greater than 8.0 , the $D_{\text {app }}$ of calycosin-7-glucoside and isomucronulatol 7-O-glucoside significantly decreased. 


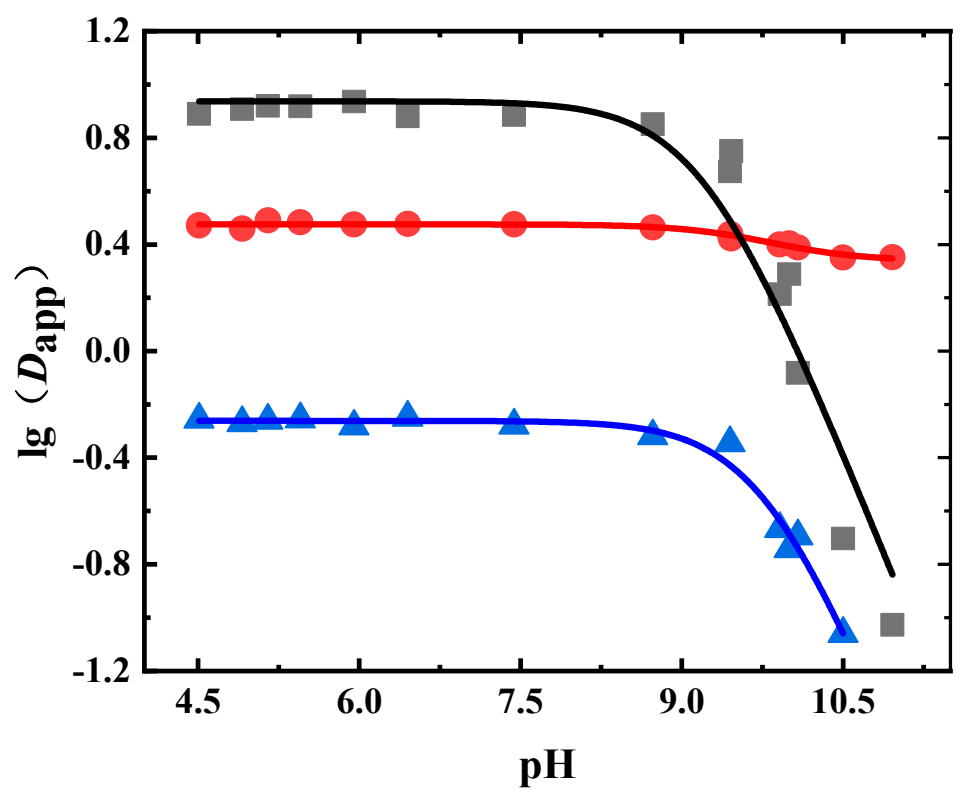

Figure 6. Experimental and fitted results of the $D_{\text {app }}$ of glycosides in Radix Astragali. (•: astraisoflavan-7O- $\beta$-D-glucoside, $\mathbf{\square}$ : isomucronulatol 7-O-glucoside, $\mathbf{\Delta}$ : calycosin-7-glucoside, solid line: fitted results).

The obtained $D_{\text {app }}$ values were fitted, where the fitting results are shown in Table 6 . The $\mathrm{pK}_{\mathrm{a}}$ value obtained by this fitting corresponds to the ionization of the phenolic hydroxyl group. From Table 6, it can be seen that the $D_{\text {app }}$ fitting results of isomucronulatol 7O-glucoside, astraisoflavan-7-O- $\beta$-D-glucoside, and calycosin-7-glucoside in the Radix Astragali extract were also satisfactory, with $R^{2}$ values greater than 0.94 . The $\mathrm{pK}_{\mathrm{a}}$ values were between 9.1-9.8. The $\log P$ values of isomucronulatol 7-O-glucoside, astraisoflavan-7$\mathrm{O}-\beta$-D-glucoside, and calycosin-7-glucoside were $0.94,0.48$, and -0.26 , respectively.

Table 6. The $\mathrm{pK}_{\mathrm{a}}$ fitting results of glycosides in Radix Astragali.

\begin{tabular}{ccccc}
\hline Glycoside & $\boldsymbol{d}_{\mathbf{0}}$ & $\boldsymbol{d}_{\mathbf{1}}$ & $\mathbf{p K}_{\mathbf{a}}$ & $\boldsymbol{R}^{\mathbf{2}}{ }_{\text {adj }}$ \\
\hline Isomucronulatol 7-O-glucoside & $0.94 \pm 0.06$ & -20 & $9.19 \pm 0.10$ & 0.940 \\
Astraisoflavan-7-O- $\beta$-D-glucoside & $0.48 \pm 0.01$ & $0.34 \pm 0.01$ & $9.76 \pm 0.10$ & 0.964 \\
Calycosin-7-glucoside & $-0.26 \pm 0.01$ & -20 & $9.78 \pm 0.03$ & 0.981 \\
\hline
\end{tabular}

\subsection{Comparison between the Experimental Values and Literature Values}

In order to check the reliability of the test results, the $\log P$ and pKa values were predicted using Discovery Studio (V3.1, BIOVIA, Paris, France), which is widely used in ADMET (Absorption, Distribution, Metabolism, Excretion, and Toxicity), QSAR (Quantitative Structure-Activity Relationship), pharmacophore model prediction, and virtual screening [21-24]. In addition, we also compared the $\mathrm{pK}_{\mathrm{a}}$ results with those reported in the literature. The comparison between the $\mathrm{pK}_{\mathrm{a}}$ results found in this work, the prediction value from the software, and those in the literature are listed in Table 7.

In Table 7, the $\mathrm{pK}_{\mathrm{a}}$ values obtained in this work are close to the reported values, which indicates that the results obtained in this work are relatively reliable. The prediction values from Discovery Studio were also close to the results from experiments on most occasions. For many organic acids, the predicted $\mathrm{pK}_{\mathrm{a}}$ values were a little lower than those reported in this work. 
Table 7. The comparison between the $\mathrm{pK}_{\mathrm{a}}$ results of this work, the prediction values using software (Discovery Studio V3.1), and those in the literature.

\begin{tabular}{|c|c|c|c|}
\hline Active Ingredients & Literature Values & Prediction Values Using Software & Results of This Work \\
\hline Sinomenine & $\begin{array}{l}\mathrm{pK}_{\mathrm{a}, 1}: 7.98[25] \\
\mathrm{pK}_{\mathrm{a}, 2}: 11.2[26]\end{array}$ & $\begin{array}{l}\mathrm{pK}_{\mathrm{a}, 1}: 7.45 \\
\mathrm{pK}_{\mathrm{a}, 2}: 7.67\end{array}$ & $\begin{array}{r}\mathrm{pK}_{\mathrm{a}, 1}: 8.01,8.10,8.40,8.53 \\
\mathrm{pK}_{\mathrm{a}, 2}: 11.52,11.59,11.25,10.81\end{array}$ \\
\hline Aescin A & - & 2.77 & $2.83 \pm 0.14$ \\
\hline Aescin B & - & 2.77 & $3.42 \pm 0.16$ \\
\hline Aescin C & - & 2.77 & $3.10 \pm 0.84$ \\
\hline Aescin D & - & 2.77 & $4.24 \pm 0.18$ \\
\hline Chlorogenic acid & $\begin{array}{l}3.59[27] \\
3.58[28] \\
3.90[29]\end{array}$ & 2.66 & $3.44 \pm 0.03$ \\
\hline Neochlorogenic acid & $3.91[29]$ & 2.66 & $3.46 \pm 0.04$ \\
\hline Cryptochlorogenic acid & $4.07[29]$ & 2.66 & $3.33 \pm 0.04$ \\
\hline Isochlorogenic acid A & - & 2.66 & $3.50 \pm 0.02$ \\
\hline Isochlorogenic acid B & - & 2.66 & $3.31 \pm 0.02$ \\
\hline Isochlorogenic acid C & - & 2.66 & $3.31 \pm 0.02$ \\
\hline $\begin{array}{l}\text { Isomucronulatol } \\
7-O \text {-glucoside }\end{array}$ & - & 11.9 & $9.19 \pm 0.10$ \\
\hline $\begin{array}{l}\text { Astraisoflavan-7-O- } \beta-\mathrm{D}- \\
\text { glucoside }\end{array}$ & - & 11.9 & $9.76 \pm 0.10$ \\
\hline Calycosin-7-glucoside & - & 10.4 & $9.78 \pm 0.03$ \\
\hline Baicalin & - & 2.86 & $2.10 \pm 0.08$ \\
\hline Wogonoside & 3.99 [30] & 2.86 & $2.17 \pm 0.08$ \\
\hline
\end{tabular}

The comparison between the $\log P$ results of this work and the prediction values of Discovery Studio can be seen in Table 8 . The $\log P$ values of sinomenine were very close. However, for the $\log P$ values of other ingredients, the deviation was remarkable.

Table 8. The comparison between the $\log P$ results of this work and the prediction values using software.

\begin{tabular}{ccc}
\hline Active Ingredient & Prediction Values Using Software & Results of This Work \\
\hline Sinomenine & 1.674 & $1.55 \pm 0.12$ \\
Chlorogenic acid & -0.340 & $0.85 \pm 0.01$ \\
Neochlorogenic acid & -0.340 & $0.19 \pm 0.01$ \\
Cryptochlorogenic acid & -0.340 & $0.62 \pm 0.01$ \\
Isochlorogenic acid A & 1.687 & $2.46 \pm 0.01$ \\
Isochlorogenic acid B & 1.687 & $2.01 \pm 0.01$ \\
Isochlorogenic acid C & 1.687 & $2.80 \pm 0.01$ \\
Isomucronulatol 7-O-glucoside & 1.249 & $0.94 \pm 0.06$ \\
Astraisoflavan-7-O-B-D-glucoside & 1.249 & $0.48 \pm 0.01$ \\
Calycosin-7-glucoside & 0.436 & $-0.26 \pm 0.01$ \\
Baicalin & 0.608 & $1.10 \pm 0.06$ \\
Wogonoside & 0.833 & $1.44 \pm 0.07$ \\
\hline
\end{tabular}

The determination method used in this work also has certain limitations. For example, in different solvents, the measured $\mathrm{pK}_{\mathrm{a}}$ values will have certain differences. When the extraction capacity of the solvent is too large, the concentration of the ingredient in the aqueous phase will be too low, which usually leads to difficulties in making concentration measurements. 


\subsection{Suitable Mobile Phase for the HPLC Analysis of Each Ingredient}

Because the $\mathrm{pH}$ value of the mobile phase influences the dissociation of these ingredients, the $\mathrm{pK}_{\mathrm{a}}$ value of each active ingredient can be used as a reference when choosing a mobile phase for HPLC analysis. It is suggested that the $\mathrm{pH}$ value of the mobile phase should be smaller than the $\mathrm{pK}_{\mathrm{a}}$ when analyzing organic acids using reversed-phase HPLC [31]. Some suitable mobile phases for the HPLC analysis for these active ingredients are listed in Table 9. It can be seen from Table 9 that the $\mathrm{pH}$ value of the mobile phase for analyzing sinomenine was 9.0. According to the results in Table 2, most sinomenine was in its molecular form at a $\mathrm{pH}$ value of 9.0. The $\mathrm{pH}$ values of other mobile phases listed in Table 9 were measured. Most of the mobile phase was present at a low $\mathrm{pH}$ value, which can inhibit the dissociation of these active ingredients.

Table 9. Some of the reported high-performance liquid chromatography (HPLC) analysis conditions of each ingredients.

\begin{tabular}{|c|c|c|}
\hline Active Ingredients & Suitable Mobile Phase for HPLC Analysis & pH Range of Mobile Phase \\
\hline Sinomenine in Caulis Sinomenii & $\begin{array}{l}\text { Methanol phosphate buffer }(0.005 \mathrm{~mol} / \mathrm{L} \\
\text { disodium hydrogen phosphate solution, } \\
0.005 \mathrm{~mol} / \mathrm{L} \text { sodium hydrogen phosphate } \\
\text { adjusted to pH 8.0, and } 1 \% \text { triethylamine } \\
\text { adjusted to pH 9.0) (55:45) [32] }\end{array}$ & 9.0 \\
\hline Aescins in Semen Aesculi & $\begin{array}{l}\text { Acetonitrile-water-phosphoric acid } \\
(123: 277: 7)[33]\end{array}$ & 1.5 \\
\hline Phenolic acids in Flos Lonicerae & $\begin{array}{l}\text { Methanol (A) and } 0.1 \% \text { phosphoric acid } \\
\text { aqueous solution (B) using the following } \\
\text { gradient program: } 0-20 \mathrm{~min}, 12-30 \% \mathrm{~A} ; \\
20-60 \mathrm{~min}, 30-50 \% \text { A [34] }\end{array}$ & $2.0-2.7$ \\
\hline Flavonoids in Radix Scutellariae & $\begin{array}{l}0.2 \% \text { phosphoric acid-water }(\mathrm{A}) \text { and } \\
\text { methanol (B) using the } \\
\text { following gradient program: } 45-45 \% \text { B, } 0-10 \\
\text { min; } 45-70 \% \text { B, } 10-55 \text { min [19] }\end{array}$ & $2.2-2.8$ \\
\hline Glycosides in Radix Astragali & $\begin{array}{l}0.05 \% \text { formic acid-water (A) and acetonitrile } \\
\text { (B) using the } \\
\text { following gradient program: } 15-29 \% \text { B, 0-40 } \\
\text { min; } 29-40 \% \text { B, } 40-50 \text { min; } 40-40 \% \text { B, } 50-60 \\
\text { min; } 40-90 \% \text { B, } 60-70 \text { min [20] }\end{array}$ & $2.8-3.8$ \\
\hline
\end{tabular}

\section{Conclusions}

This study mainly determined the $D_{\mathrm{app}}$ and $\mathrm{pK}$ a 16 active ingredients in medicinal herbs, namely, sinomenine in Caulis Sinomenii, aescins in Semen Aesculi, phenolic acids in Flos Lonicerae, flavonoids in Radix Scutellariae, and glycosides in Radix Astragali. The $\mathrm{pK}_{\mathrm{a}, 1}$ value of sinomenine was between 8.0 and 8.6, while the $\mathrm{pK}_{\mathrm{a}, 2}$ value was between 10.8 and 11.6. Trichloromethane had the largest extraction capacity for sinomenine, with a maximum $D_{\text {app }}$ of more than 500. The $\mathrm{pK}_{\mathrm{a}}$ values of aescins $\mathrm{A}, \mathrm{B}, \mathrm{C}$, and D were similar, which were all between 2.8 and 4.3. The $\mathrm{pK}_{\mathrm{a}}$ values of six phenolic acids in Flos Lonicerae were all in the range of 3.3-3.5. The $D_{\text {app }}$ values of isochlorogenic acids $A, B$, and C in 1-octanol could reach more than 100, while the $D_{\text {app }}$ values of neochlorogenic acid, chlorogenic acid, and cryptochlorogenic acid were below 10. The $\mathrm{pK}_{\mathrm{a}}$ of baicalin and wogonoside in Radix Scutellariae were both about 2.1. The $\mathrm{pK}_{\mathrm{a}}$ values obtained by fitting the three ingredients of isomucronulatol 7-O-glucoside, astraisoflavan-7-O- $\beta$-D-glucoside, and calycosin-7-glucoside in Radix Astragalus were all between 9.10 and 9.80. The $\mathrm{pK}_{\mathrm{a}}$ and $D_{\text {app }}$ values of the 16 active ingredients examined in this work can be used in the development of the extraction process and analytical methods for these ingredients. 
Author Contributions: Investigation, W.W., B.Z. and P.L.; data curation, W.W., B.Z., J.W. and W.L.; writing-original draft preparation, W.W. and B.Z.; writing-review and editing, X.G.; supervision, X.G. All authors have read and agreed to the published version of the manuscript.

Funding: The research was funded by the National S\&T Major Project of China (2018ZX09201011002), Student Research Training Program of Zhejiang University (X20200244), and the National Project for Standardization of Chinese Materia Medica (ZYBZH-C-GD-04).

Data Availability Statement: We have listed all the data in the Appendix A.

Acknowledgments: The authors would like to thank Feng Zhu for his help in the calculations of $\mathrm{pK}_{\mathrm{a}}$ and $\log \mathrm{P}$ by Discovery Studio.

Conflicts of Interest: The authors declare no conflict of interest.

\section{Appendix A}

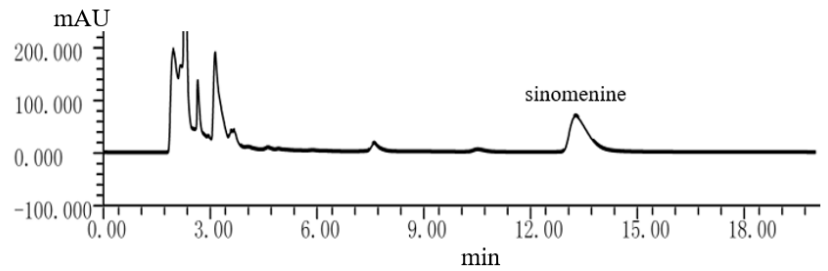

Figure A1. HPLC diagram of the Caulis Sinomenii aqueous phase.

Table A1. Experimental results of the $D_{\text {app }}$ values of sinomenine that were obtained in four liquidliquid equilibrium systems.

\begin{tabular}{cccccccc}
\hline \multicolumn{2}{c}{ 1-Butanol } & \multicolumn{2}{c}{ Trichloromethane } & \multicolumn{2}{c}{ Methyl Isobutyl Ketone } & \multicolumn{2}{c}{ 1-Octanol } \\
\hline $\mathbf{p H}$ & $\boldsymbol{D}_{\text {app }}$ & $\mathbf{p H}$ & $\boldsymbol{D}_{\text {app }}$ & $\mathbf{p H}$ & $\boldsymbol{D}_{\text {app }}$ & $\mathbf{p H}$ & $\boldsymbol{D}_{\text {app }}$ \\
\hline 1.871 & 0.636 & 4.925 & 0.510 & 5.071 & 0.002 & 5.053 & 0.068 \\
4.188 & 0.769 & 5.156 & 0.717 & 6.804 & 0.027 & 6.258 & 0.175 \\
6.197 & 2.073 & 5.180 & 0.871 & 7.015 & 0.047 & 6.729 & 0.961 \\
7.366 & 10.70 & 6.609 & 24.36 & 7.520 & 0.134 & 7.562 & 2.981 \\
7.596 & 16.54 & 6.862 & 37.69 & 8.309 & 0.317 & 8.236 & 11.28 \\
7.826 & 27.13 & 7.062 & 46.37 & 8.429 & 0.483 & 8.703 & 20.63 \\
8.264 & 39.87 & 7.071 & 55.50 & 9.226 & 0.939 & 9.688 & 24.05 \\
9.413 & 59.42 & 7.471 & 82.10 & 10.03 & 1.067 & 9.730 & 40.90 \\
9.523 & 56.52 & 7.990 & 165.5 & 12.50 & 0.054 & 11.82 & 4.769 \\
9.954 & 64.25 & 8.788 & 481.2 & 12.63 & 0.041 & 11.83 & 2.005 \\
10.08 & 62.42 & 9.723 & 574.3 & - & - & - & - \\
10.20 & 57.92 & 10.99 & 571.7 & - & - & - & - \\
11.00 & 44.59 & 11.42 & 348.2 & - & - & - & - \\
11.19 & 44.88 & 12.11 & 123.6 & - & - & - & - \\
11.94 & 18.30 & - & - & - & - & - & - \\
12.13 & 11.74 & - & - & - & & -
\end{tabular}

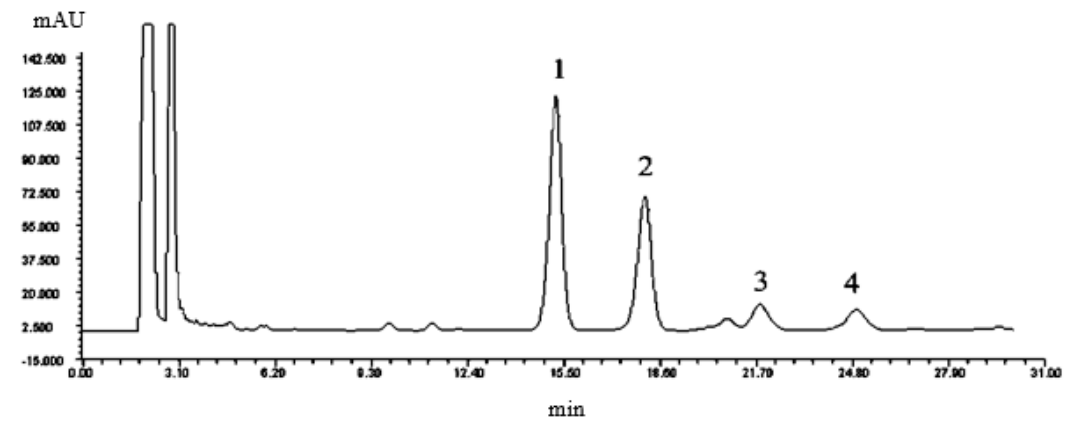

Figure A2. HPLC diagram of the Semen Aesculi organic phase (1: aescin A, 2: aescin B, 3: aescin C, 4 : aescin D). 
Table A2. Experimental results of the $D_{\text {app }}$ values of aescins in Semen Aesculi obtained in a 1butanol system.

\begin{tabular}{ccccc}
\hline pH & Aescin A & Aescin B & Aescin C & Aescin D \\
\hline 2.624 & 801.4 & 309.0 & - & - \\
3.332 & 383.5 & 431.1 & - & - \\
3.995 & 75.03 & - & 130.0 & 105.5 \\
4.030 & 80.79 & 121.3 & 74.50 & - \\
4.171 & - & 148.2 & 99.03 & - \\
4.223 & 46.28 & 55.71 & 50.88 & 67.76 \\
4.654 & 21.11 & 24.25 & 25.16 & 37.42 \\
4.839 & 17.48 & 20.06 & 19.16 & 32.24 \\
5.162 & 10.04 & 11.25 & 13.23 & 14.47 \\
5.331 & 7.489 & 8.220 & 7.279 & 9.521 \\
5.819 & 5.210 & 5.745 & 4.554 & 6.298 \\
6.073 & 4.608 & 5.036 & 3.940 & 5.390 \\
6.317 & 3.942 & 4.349 & 3.357 & 4.269 \\
6.737 & 4.321 & 4.712 & 3.207 & 4.121 \\
6.811 & 4.185 & 4.501 & 2.954 & 3.685 \\
\hline
\end{tabular}

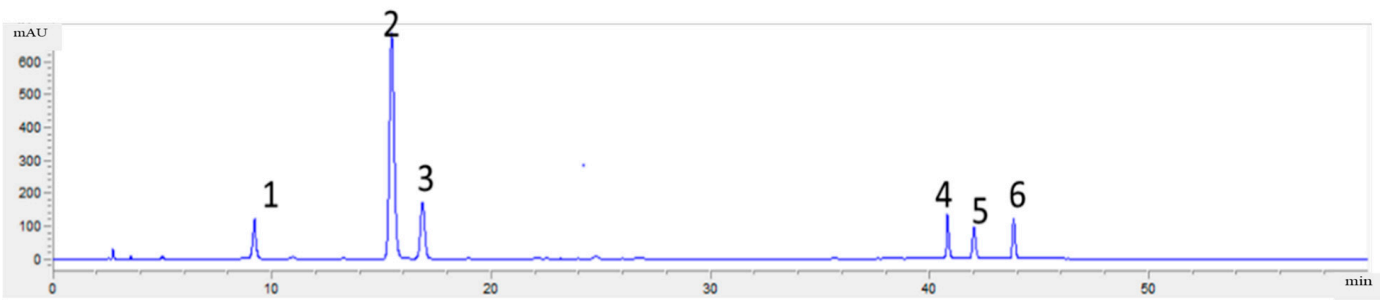

Figure A3. HPLC diagram of the Flos Lonicerae organic phase (1: neochlorogenic acid, 2: chlorogenic acid, 3: cryptochlorogenic acid, 4: isochlorogenic acid B, 5: isochlorogenic acid A, 6: isochlorogenic acid C).

Table A3. Experimental results of the $D_{\text {app }}$ values of phenolic acids in Flos Lonicerae obtained in the 1-octanol system.

\begin{tabular}{|c|c|c|c|c|c|c|}
\hline $\mathrm{pH}$ & $\begin{array}{c}\text { Neochlorogenic } \\
\text { Acid }\end{array}$ & $\begin{array}{l}\text { Chlorogenic } \\
\text { Acid }\end{array}$ & $\begin{array}{c}\text { Cryptochlorogenic } \\
\text { Acid }\end{array}$ & $\begin{array}{l}\text { Isochlorogenic } \\
\text { Acid B }\end{array}$ & $\begin{array}{c}\text { Isochlorogenic } \\
\text { Acid A }\end{array}$ & $\begin{array}{c}\text { Isochlorogenic } \\
\text { Acid C }\end{array}$ \\
\hline 4.910 & 0.054 & 0.254 & 0.112 & 2.527 & 10.89 & 15.80 \\
\hline 4.530 & 0.128 & 0.581 & 0.270 & 5.800 & 25.00 & 37.02 \\
\hline 4.200 & 0.245 & 1.104 & 0.524 & 12.24 & 49.84 & 73.58 \\
\hline 3.690 & 0.552 & 2.474 & 1.241 & 29.51 & 112.3 & 181.5 \\
\hline 3.200 & 0.935 & 4.201 & 2.228 & 54.28 & 181.7 & 326.9 \\
\hline 2.730 & 1.339 & 5.905 & 3.326 & 83.89 & 259.9 & 506.8 \\
\hline 2.350 & 1.314 & 6.009 & 3.444 & 87.93 & 281.2 & 545.1 \\
\hline 1.860 & 1.435 & 6.852 & 3.971 & 97.22 & 278.2 & 594.8 \\
\hline 1.660 & 1.699 & 7.606 & 4.507 & 106.7 & 300.3 & 669.1 \\
\hline 1.520 & 1.572 & 7.310 & 4.337 & 100.0 & 271.6 & 632.7 \\
\hline
\end{tabular}

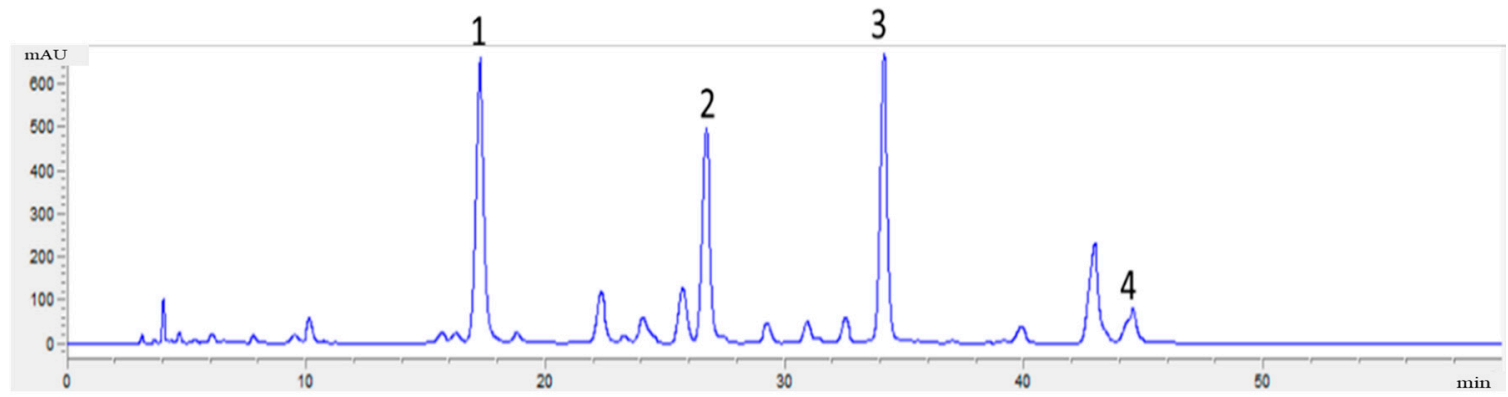

Figure A4. HPLC diagram of the Radix Scutellariae organic phase (1: baicalin, 2: wogonoside). 
Table A4. Experimental results of the $D_{\text {app }}$ values of flavonoids in Radix Scutellariae obtained in the 1-octanol system.

\begin{tabular}{ccc}
\hline $\mathbf{p H}$ & Baicalin & Wogonoside \\
\hline 5.360 & 0.009 & 0.018 \\
4.800 & 0.031 & 0.062 \\
4.430 & 0.055 & 0.122 \\
3.950 & 0.148 & 0.347 \\
3.690 & 0.315 & 0.861 \\
3.260 & 0.777 & 2.337 \\
2.860 & 2.678 & 6.800 \\
2.040 & 7.073 & 16.67 \\
1.680 & 8.796 & 19.99 \\
1.520 & 9.658 & 20.98 \\
\hline
\end{tabular}

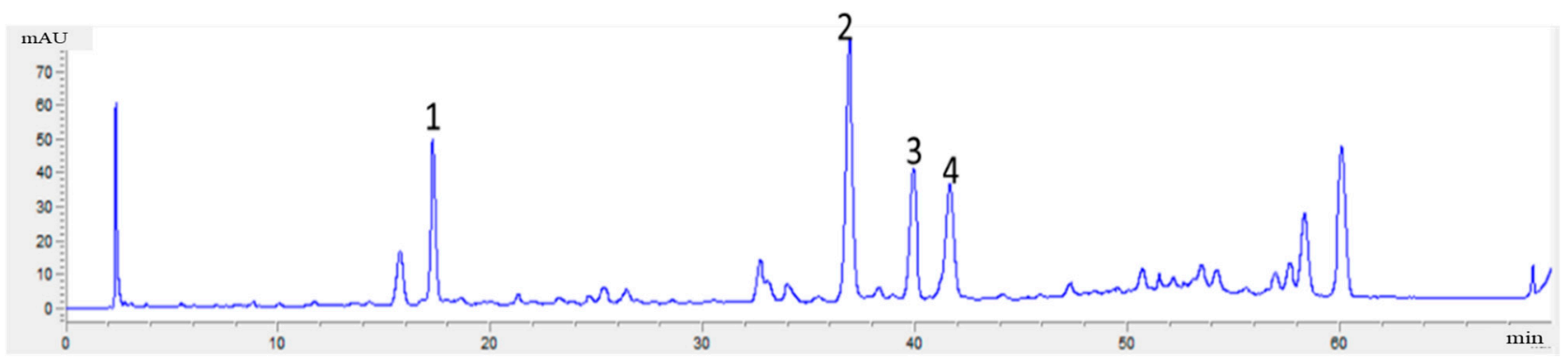

Figure A5. HPLC diagram of the Radix Astragali organic phase (1: calycosin-7-glucoside, 2 : astraisoflavan-7-O- $\beta$-Dglucoside, 3: isomucronulatol 7-O-glucoside).

Table A5. Experimental results of the $D_{\text {app }}$ values of flavonoids in Radix Astragali obtained in the 1-octanol system.

\begin{tabular}{cccc}
\hline $\mathbf{p H}$ & $\begin{array}{c}\text { Isomucronulatol } \\
\text { 7-O-Glucoside }\end{array}$ & $\begin{array}{c}\text { Astraisoflavan-7-O- } \\
\beta-D-G l u c o s i d e\end{array}$ & $\begin{array}{c}\text { Calycosin-7- } \\
\text { Glucoside }\end{array}$ \\
\hline 10.96 & 0.094 & 2.249 & - \\
10.500 & 0.198 & 2.245 & 0.087 \\
10.08 & 0.828 & 2.449 & 0.202 \\
10.00 & 1.947 & 2.538 & 0.181 \\
9.910 & 1.635 & 2.513 & 0.215 \\
9.460 & 5.632 & 2.645 & 1.030 \\
9.450 & 4.724 & 2.753 & 0.452 \\
8.730 & 7.099 & 2.914 & 0.480 \\
7.440 & 7.681 & 2.990 & 0.526 \\
6.450 & 7.594 & 3.001 & 0.564 \\
5.950 & 8.639 & 2.987 & 0.522 \\
5.450 & 8.294 & 3.042 & 0.556 \\
5.150 & 8.320 & 3.094 & 0.549 \\
4.910 & 8.095 & 2.882 & 0.537 \\
4.510 & 7.764 & 2.964 & 0.554 \\
\hline
\end{tabular}

\section{References}

1. Alexovic, M.; Dotsikas, Y.; Bober, P.; Sabo, J. Achievements in robotic automation of solvent extraction and related approaches for bioanalysis of pharmaceuticals. J. Chromatogr. B Anal. Technol. Biomed. Life Sci. 2018, 1092, 402-421. [CrossRef]

2. Machado, T.C.; Kuminek, G.; Cardoso, S.G.; Rodriguez-Hornedo, N. The role of pH and dose/solubility ratio on cocrystal dissolution, drug supersaturation and precipitation. Eur. J. Pharm. Sci. 2020, 152, 105422. [CrossRef]

3. Santos Lins, P.V.; Henrique, D.C.; Ide, A.H.; da Silva Duarte, J.L.; Dotto, G.L.; Yazidi, A.; Sellaoui, L.; Erto, A.; de Paiva e Silva Zanta, C.L.; Meili, L. Adsorption of a non-steroidal anti-inflammatory drug onto MgAl/LDH-activated carbon composite-Experimental investigation and statistical physics modeling. Colloids Surf. A Physicochem. Eng. Asp. 2020, 586, 124217. [CrossRef] 
4. Queiroz, A.L.P.; Wood, B.; Faisal, W.; Farag, F.; Garvie-Cook, H.; Glennon, B.; Vucen, S.; Crean, A.M. Application of percolation threshold to disintegration and dissolution of ibuprofen tablets with different microcrystalline cellulose grades. Int. J. Pharm. 2020, 589, 119838. [CrossRef]

5. Wiedenbeck, E.; Gebauer, D.; Cölfen, H. Potentiometric titration method for the determination of solubility limits and pK(a) values of weak organic acids in water. Anal. Chem. 2020, 92, 9511-9515. [CrossRef]

6. Celebier, M.; Kocak, E.; Dogan, A.; Altinoz, S.; Basci, N.E. Investigating the physicochemical properties of phenazopyridine hydrochloride using high-performance liquid chromatography and UV-visible spectrophotometry. J. Res. Pharm. 2018, 22, 528-535. [CrossRef]

7. Gong, S.; Su, X.; Bo, T.; Zhang, X.; Liu, H.; Li, K. Determination of dissociation constants of ten alkaloids by capillary zone electrophoresis. J. Sep. Sci. 2003, 26, 549-554. [CrossRef]

8. Huo, H.; Li, T.; Zhang, L. pK(a) determination of oxysophocarpine by reversed-phase high performance liquid chromatography. Springerplus 2013, 2, 270. [CrossRef] [PubMed]

9. Read, A.J. Ionization-constants of aqueous ammonia from 25 to $250{ }^{\circ} \mathrm{C}$ and to 2000 bar. J. Solut. Chem. 1982, 11, 649-664. [CrossRef]

10. Gong, X.; Huang, S.; Jiao, R.; Pan, J.; Li, Y.; Qu, H. The determination of dissociation constants for active ingredients from herbal extracts using a liquid liquid equilibrium method. Fluid Phase Equilibria 2016, 409, 447-457. [CrossRef]

11. Madej, K.; Kozka, G.; Winiarski, M.; Piekoszewski, W. A Simple, Fast, and Green Oil Sample Preparation Method for Determination of Cannabidioloic Acid and Cannabidiol by HPLC-DAD. Separations 2020, 7, 60. [CrossRef]

12. Sun, Y.; Zhu, Q.; Li, J. Research progress on anti-inflammatory and anti-tumor effects of sinomenine. Chin. Pharmacol. Bull. 2015, 31, 1040-1043.

13. Sirtori, C.R. Aescin: Pharmacology, pharmacokinetics and therapeutic profile. Pharmacol. Res. 2001, 44, 183-193. [CrossRef]

14. Li, Y.; Li, W.; Fu, C.; Song, Y.; Fu, Q. Lonicerae japonicae flos and Lonicerae flos: A systematic review of ethnopharmacology, phytochemistry and pharmacology. Phytochem. Rev. 2020, 19, 1-61. [CrossRef] [PubMed]

15. Shen, J.; Li, P.; Liu, S.; Liu, Q.; Li, Y.; Sun, Y.; He, C.; Xiao, P. Traditional uses, ten-years research progress on phytochemistry and pharmacology, and clinical studies of the genus Scutellaria. J. Ethnopharmacol. 2021, 265, 113198. [CrossRef]

16. Lyu, Q.; Zhao, W.; Wang, S.; Teng, J.; Xin, D.; Li, J.; Kong, X. Effect of Astragali Radix Membranaceus in promoting blood circulation and its modern pharmacology research. Chin. J. Exp. Tradit. Med. Formulae 2020, 26, 215-224.

17. Cao, Y.; Zhang, C.; Zhu, M.; Yang, G. Comparison of Different Extraction Methods of $\beta$-aescin A, B from Three Different Aesculi Semens in Wudang Area. J. Hubei Univ. Med. 2018, 37, 161-163.

18. Wang, L.N.; Liu, H.Y.; Zhang, J.; Li, J.; Zhang, Y.Q. Simultaneous determination of eight Bioactive components in lonicerae japonicae flos by quantitative analysis of multi-components by single marker. Chin. J. Exp. Tradit. Med. Formulae 2014, $20,57-61$.

19. Zhu, J.; Wang, Z.; Zhang, Q.; Niu, J.; Li, F. A quantitative method for simultaneous assay of four flavones with one marker in Radix Scutellariae. China J. Chin. Mater. Med. 2009, 34, 3229-3234.

20. Chen, X.; Li, Q.; Tan, X.; Wang, P.; Bi, K. RP-HPLC simultaneous determination of six flavonoids in Radix Astragali. Chin. J. Pharm. Anal. 2009, 29, 1115-1118.

21. Ma, Y.; Jin, Y.; Wang, Y.; Wang, R.; Lu, X.; Kong, D.; Xu, W. The discovery of a novel and selective inhibitor of PTP1B over TCPTP: 3D QSAR pharmacophore modeling, virtual screening, synthesis, and biological evaluation. Chem. Biol. Drug Des. 2014, 83, 697-709. [CrossRef] [PubMed]

22. Yin, J.; Li, F.; Zhou, Y.; Mou, M.; Lu, Y.; Chen, K.; Xue, J.; Luo, Y.; Fu, J.; He, X.; et al. INTEDE: Interactome of drug-metabolizing enzymes. Nucleic Acids Res. 2021, 49, D1233-D1243. [CrossRef]

23. Chokshi, A.B.; Chhabria, M.T.; Desai, P.R. Rational Discovery of Novel Squalene Synthase Inhibitors through Pharmacophore Modelling. Curr. Comput. Aided Drug Des. 2018, 14, 221-233. [CrossRef] [PubMed]

24. Jiang, Y.; Gao, H. Pharmacophore-based drug design for the identification of novel butyrylcholinesterase inhibitors against Alzheimer's disease. Phytomed. Int. J. Phytother. Phytopharm. 2019, 54, 278-290. [CrossRef] [PubMed]

25. Li, Z.; Tian, S.; Gu, H.; Wu, Z.; Nyagblordzro, M.; Feng, G.; He, X. In vitro-in vivo predictive dissolution-permeation-absorption dynamics of highly permeable drug extended-release tablets via drug dissolution/absorption simulating system and $\mathrm{pH}$ alteration. AAPS PharmSciTech 2018, 19, 1882-1893. [CrossRef] [PubMed]

26. Zhu, S. Degradation Mechanism and Mateiral Behaviors Analysis of the Inclusion Complexes of Sinomenine to Cyclodextrins. Master's Thesis, Jishou University, Jishou, China, 2012.

27. Xu, H.; Xu, Y. Simultaneous Determination of Three Phenolic Acid in Pugongying Granules by High Performance Liquid Chromatography-Mass Spectrometry. Chemistry 2008, 71, 415-419.

28. Moridani, M.Y.; Scobie, H.; Jamshidzadeh, A.; Salehi, P.; O’Brien, P.J. Caffeic acid, chlorogenic acid, and dihydrocaffeic acid metabolism: Glutathione conjugate formation. Drug Metab. Dispos. 2001, 29, 1432-1439.

29. Tang, B.; Huang, Y.; Ma, X.; Liao, X.; Wang, Q.; Xiong, X.; Li, H. Multispectroscopic and docking studies on the binding of chlorogenic acid somers to human serum albumin: Effects of esteryl position on affinity. Food Chem. 2016, 212, 434-442. [CrossRef]

30. Wang, C.; Zuo, G.; Wang, X.; Kim, H.Y.; Zhao, S.; Sun, W.; Tong, S.; Lim, S.S. Retention mechanism of pH-peak-focusing in countercurrent chromatographic separation of baicalin and wogonoside fromScutellaria baicalensisGeorgi. J. Sep. Sci. 2020, 43, 3806-3815. [CrossRef] 
31. Guo, Z.; Chang, J.; Wang, W. Study on Reversed-Phase High Performance Liquid Chromatography Separation Condition and Determination Method of Organic Acids. Chin. J. Chromatogr. 2001, 19, 260.

32. Yan, H.; Ma, S. RP-HPLC determination of sinomenine in Caulis Sinomenii. Chin. J. Pharm. Anal. 2006, 26, 201-203.

33. Guo, J.; Xu, W.; Yang, X. Quantified analysis of triterpenoid saponins in Semen Aesculi by HPLC. Chin. Tradit. Herb. Drugs 2007, $38,767-770$.

34. Li, M.; Wang, Y.; Meng, J.; Fu, X.; Bi, Y.; Wang, Z.; Xiao, W. Determination of eight components in Lonicerae Japonicae Flos by HPLC. Chin. Tradit. Herb. Drugs 2014, 45, 1006-1010. 